\title{
Chemical analysis of some Ocimum basilicum medicinal teas
}

\author{
Daniela BENEDEC, Diana ROZSA (RUS), Daniela HANGANU, Ilioara ONIGA \\ Department of Pharmacognosy, Faculty of Pharmacy, "Iuliu Hatieganu" University of Medicine and Pharmacy, \\ Cluj-Napoca, Romania
}

\begin{abstract}
Objectives. Ocimum basilicum is one of the widespread medicinal plants, widely used due to its multiple therapeutic properties (antimicrobial, antiviral, hypoglycemic, antispasmodic, anti-inflammatory, carminative, stomachic, antioxidant, analgesic, etc.), as well as its specific aromatic character. The aim of this study was to comparatively investigate the chemical composition (flavonoids, caffeic acid derivatives, tannins, essential oil) of the aerial parts of some Romanian medicinal teas of Ocimum basilicum.

Materials and methods. The content of flavonoids, phenolic acids and tannins in three samples of $\mathrm{O}$. basilicum tea were determined spectrophotometrically. Identification of important phenolic compounds (rutin, isoquercitrin chlorogenic acid and caffeic acid) was performed by thin layer chromatography (TLC). The essential oils were obtained by hydrodistillation method.

Outcomes and conclusions. Following the quantitative determinations performed, it can be seen that the basil samples are rich in active principles, and their use for the treatment of some diseases can be justified.
\end{abstract}

Keywords: Ocimum basilicum, tea, flavonoids, acid caffeic derivatives, tannins, essential oils

\section{INTRODUCTION}

Ocimum basilicum L.(basil, Lamiaceae family) is an aromatic medicinal plant and is a rich source of bioactive principles [1-5]. Basil is a plant cultivated in many areas of Romania and is frequently used for medicinal purposes and to specific flavor. The aerial parts (Basilici herba) contain essential oil (with linalool, methyl chavicol, 1,8-cineole, eugenol, methyleugenol or methyl cinnamate), polyphenols (flavonoids, caffeic acid derivatives, etc.), triterpene acids, phytosterols, with antimicrobial, diuretic, antioxidant, digestive stimulant properties.

Traditionally, sweet basil has been used as a medicinal plant in the treatment of headaches, coughs, warts, worms, and kidney malfunctions. The essential oil has antimicrobial, antifungal, insect-repelling, antioxidant activities [6-8].

The purpose of this research was the chemical analysis of some vegetal raw materials from three medicinal teas of $O$. basilicum from the Romanian market, in order to evaluate the quality of commercial products.

\section{MATERIALS AND METHODS}

\section{Plant material and preparation of extracts}

The plant materials were three medicinal basil teas (B1, B2, B3) purchased on the Romanian pharmaceutical market, from three commercial companies, which were ground to a fine powder. The 
plant materials were extracted at $60^{\circ} \mathrm{C}$ using $70 \%$ ethanol, on water bath (30 minutes). The ethanolic extracts obtained were filtered and made up to volume $(50 \mathrm{ml})$ in volumetric flasks $[9,10]$.

\section{Determination of flavonoidic contents}

The flavonoids contents were determined using $\mathrm{AlCl} 3$ reagent, by a spectrophotometric test. $10 \mathrm{ml}$ of each ethanolic extract were diluted with methanol. To $5 \mathrm{ml}$ of solution was added $5 \mathrm{ml}$ of sodium acetate $(100 \mathrm{~g} / \mathrm{l})$ and $3 \mathrm{ml}$ of aluminum chloride $(25 \mathrm{~g} / \mathrm{l})$. The absorbance of the solutions was measured at $430 \mathrm{~nm}$. Rutin was used as a standard for the preparation of a calibration curve $(\mathrm{R} 2=0.999)$. The results were expressed as a percentage ( $\mathrm{g}$ of rutin equivalents (RE)/100 g of dry plant material) [10-12].

\section{Determination of caffeic acid derivatives contents}

The caffeic acid derivatives contents were determined using a spectrophotometric method with Arnow reagent in basic medium ( $\mathrm{NaOH}$ ), method described in the Cynarae folium monograph [12]. $5 \mathrm{ml}$ of extract ethanolic were diluted with $50 \mathrm{ml}$ ethanol in a volumetric flask (solution $\mathrm{A}$ ). To $1 \mathrm{ml}$ of solution $\mathrm{A}$ were added: $1 \mathrm{ml}$ sodium hydroxide (1N), $1 \mathrm{ml}$ Arnow regent, $1 \mathrm{ml} \mathrm{HCl}(1 \mathrm{M})$ and $10 \mathrm{ml}$ water. Absorbance was measured at $500 \mathrm{~nm}$. The phenolic acids contents were expressed as caffeic acid equivalent (g CAE/100 g dry plant material), using an equation derived from the from the calibration curve of caffeic acid (R2 = 0.994) [9-12].

\section{Determination of tannin contents}

Quantitative analysis of tannins was performed according to an indirect photocolorimetric technique, after a prior color reaction of polyphenols with phosphorulfamic acid, in basic medium [9,12]. First, the absorbance of the total polyphenolic (A1) was determined at $715 \mathrm{~nm}$. In the second step, after the adsorption of the tannins on the skin powder, the absorbance of the polyphenols (A2) was measured. The pyrogalol was used as the standard solution. The concentration of the tannins was calculated using the relation: $\mathrm{C}(\%)=[62,5 \cdot \mathrm{m} 1 \cdot \mathrm{A} 1-\mathrm{A} 2)] / \mathrm{A} 3 \cdot \mathrm{m} 2(\mathrm{~A} 1=$ absorbance of the total polyphenol solution; $A 2=$ absorbance of the solution of unabsorbed polyphenols on the skin powder; $\mathrm{A} 3$ = absorbance of the pyrogalol solution $(0.31) ; \mathrm{m} 1=$ mass of pirogalol $(0.05 \mathrm{~g}) ; \mathrm{m} 2$ = mass of the sample used in work (Table 1) [9].

\section{Determination of essential oil contents}

The $O$. basilicum essential oil (Basilici aetheroleum) was obtained by hydrodistillation with the Clevenger apparatus, according to the method described in FR X [12]. The results were expressed in $\mathrm{ml} / 100 \mathrm{~g}$ dry material product (Table 1) $[9,12]$.

\section{Thin-layer chromatography (TLC)}

The preliminary TLC identification of some polyphenolic compounds from Ocimum basilicum extracts (Table 2, Figure 5) was performed using a silica gel chromatographic system as the stationary phase and a mobile phase: ethyl acetate: acetic acid: formic acid: water (100: 11: 11: 26) [9].

\section{RESULTS AND DISCUSSION}

The results obtained from the quantitative determinations performed on the three basil teas are presented in Table 1.

TABLE 1. Polyphenolic and essential oils contents in some $O$. basilicum extracts

\begin{tabular}{|c|c|c|c|c|}
\hline Samples & $\begin{array}{c}\text { Flavonoids } \\
\text { (\%) }\end{array}$ & $\begin{array}{c}\text { Caffeic acid } \\
\text { derivatives } \\
\text { (\%) }\end{array}$ & $\begin{array}{c}\text { Tannins } \\
\text { (\%) }\end{array}$ & $\begin{array}{c}\text { Essential } \\
\text { oil } \\
\text { (ml/100g) }\end{array}$ \\
\hline B1 & $\mathbf{1 . 6 1}$ & $\mathbf{2 . 2 8}$ & $\mathbf{2 . 3 3}$ & $\mathbf{0 . 8 0}$ \\
\hline B2 & 1.39 & 2.02 & 2.25 & 0.60 \\
\hline B3 & 0.60 & 1.19 & 2.07 & 0.13 \\
\hline
\end{tabular}

\section{Flavonoidic contents}

The total flavonoid contents of the three $\mathrm{O}$. basilicum tea ethanolic extracts were spectrophotometrically analyzed using the aluminum chloride colorimetric method, and the results were presented in Figure 1.

The highest amount of flavonoids was found in the B1 extract (1.61\%) and B2 (1.33\%), B3 having the lowest amount of flavonoids below $1 \%$.

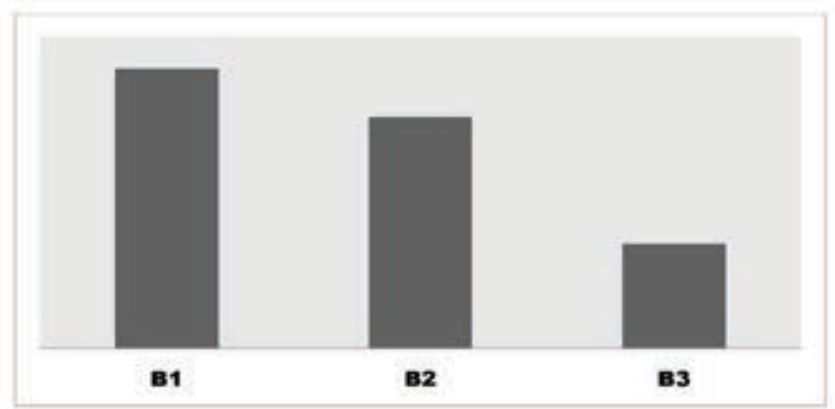

FIGURE 1. Flavonoid content in the $\mathrm{O}$. basilicum extracts 


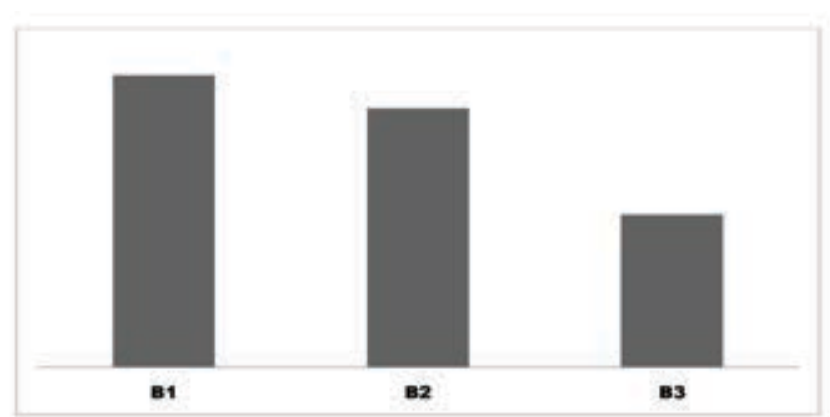

FIGURE 2. Caffeic acid derivative content in the $O$. basilicum extracts

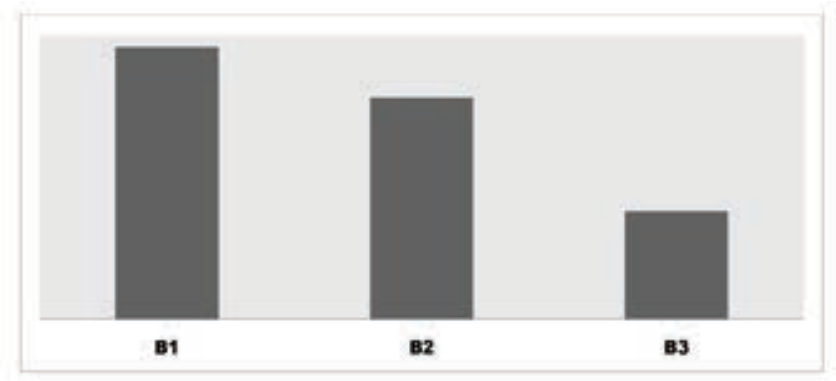

FIGURE 3. Tannins content in the $O$. basilicum extracts

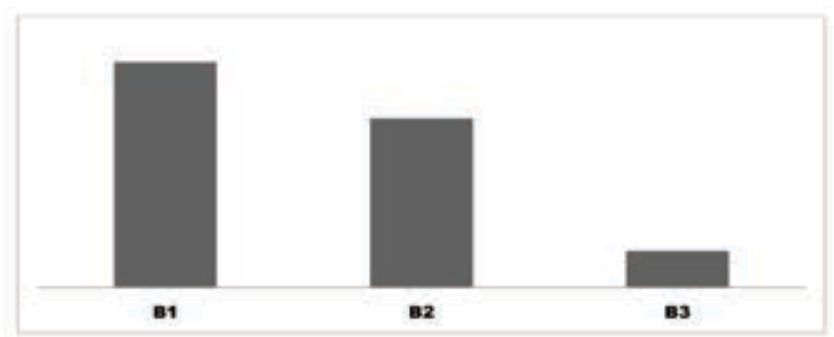

FIGURE 4. Essential oil content in 0 . basilicum

\section{Caffeic acid derivatives contents}

The amount of caffeic acid derivatives from the three ethanolic extracts of $O$. basilicum teas determined by spectrophotometry were shown in Figure 2. All samples of basil teas showed significant amounts of caffeic acids, Ocimum basilicum being a rich source of natural antioxidant polyphenols.

\section{Tannin contents}

The tannin contents of the three basil extracts were spectrophotometrically determined, and the results were shown in Figure 3. All samples of basil teas showed small amounts of tannins, between 2.07 and $2.33 \%$. The smallest amount of tannins was identified in the B3 extract (2.07\%).

\section{Essential oil contents}

Following the determinations performed, it can be seen that sample B1 is the richest in essential oil $(0.80$ $\mathrm{ml} / 100 \mathrm{~g})$, and the poorest being sample B3 $(0.13$ $\mathrm{ml} / 100 \mathrm{~g})$. In all samples of basil, small quantities, below $1 \%$, were measured, the vegetable products being poor in essential oil (Figure 4).

\section{Thin-layer chromatography}

TLC identification of polyphenolic compounds in the O. basilicum ethanolic extracts were performed using the chromatographic system with silica gel as stationary phase and the corresponding mobile phase: ethyl acetate:acetic acid: formic acid: water (100:11:11:26). The spots of standards were easy to detect and compare with samples spots. Rf values were: rutin - 0.42 (yellow-orange spot), chlorogenic acid - 0.51 (blue spot), caffeic acid - 0.96 (blue spot), and isoquercitrine -0.64 (orange spot) for corresponding mobile phase mentioned earlier. The results are presented in Figure 5 and Table 2 . In our samples, along with flavonoids (rutin and isoquercitrin), phenylpropanic acids such as caffeic acid and chlorogenic acid were also detected.

\section{TABLE 2. TLC results}

\begin{tabular}{|c|c|c|c|}
\hline Sample B1 & Sample B2 & Sample B3 & Standards \\
\hline $\begin{array}{c}\text { Rf1 }=0.42 \\
\text { yellow- } \\
\text { orange }\end{array}$ & $\begin{array}{c}\text { Rf1 }=0.42 \\
\text { yellow-orange }\end{array}$ & $\begin{array}{c}\text { Rf1 }=0.42 \\
\text { yellow- } \\
\text { orange }\end{array}$ & $\begin{array}{c}\text { rutin } \\
\text { (Rf }=0.42, \\
\text { yellow-orange) }\end{array}$ \\
\hline $\begin{array}{c}\text { Rf2 }=0.51 \\
\text { blue }\end{array}$ & $\begin{array}{c}\text { Rf2 }=0.51 \\
\text { blue }\end{array}$ & $\begin{array}{c}\mathrm{Rf} 2=0.51 \\
\text { blue }\end{array}$ & $\begin{array}{c}\text { chlorogenic acid } \\
\text { (Rf }=0.51, \text { blue) }\end{array}$ \\
\hline $\begin{array}{c}\text { Rf3 }=0.64 \\
\text { orange }\end{array}$ & $\begin{array}{c}\text { Rf3 }=0.64 \\
\text { orange }\end{array}$ & $\begin{array}{c}\text { Rf3 }=0.64 \\
\text { orange }\end{array}$ & $\begin{array}{c}\text { isoquercitrine } \\
\text { (Rf }=0.64, \\
\text { orange) }\end{array}$ \\
\hline $\begin{array}{c}\text { Rf5 }=0.91 \\
\text { blue }\end{array}$ & $\begin{array}{c}\text { Rf5 }=0.91 \\
\text { blue }\end{array}$ & $\begin{array}{c}\text { Rf5 }=0.91 \\
\text { blue }\end{array}$ & $\begin{array}{c}\text { caffeic acid } \\
\text { (Rf }=0.91, \text { blue) }\end{array}$ \\
\hline
\end{tabular}

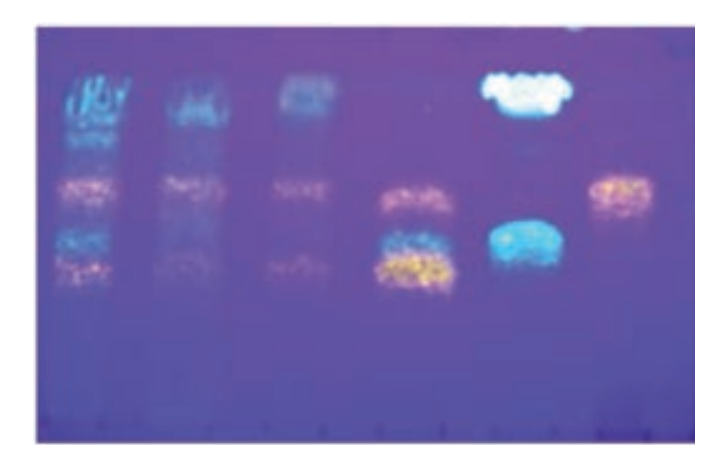

FIGURE 5. TLC plates viewed after staining with NEU/PEG reagent, under $365 \mathrm{~nm}$

\section{CONCLUSIONS}

The most important active ingredients analyzed in three Ocimum basilicum medicinal teas were essential oil and polyphenolic compounds: flavonoids, phenylpropane derivatives and tannins. 
Following the quantitative determinations performed by spectrophotometric and gravimetric methods, it can be seen that the three samples do not show significant differences in chemical composition. Thus, the vegetal materials correspond both from a qualitative and quantitative point of view, being able to be capitalized as phytotherapeutic remedies, but also as valuable spices.

Conflict of interest: none declared Financial support: none declared

\section{REFERENCES}

1. Ciocârlan V. Flora ilustrată a României, Pteridophyta et Spermatophyta București: Editura Ceres; 2009.

2. Muntean LS, Tămaş $M$, Muntean $S$, Muntean L, Duda $M$, Vârban D, Florian S. Tratat de plante medicinale cultivate şi spontane, Ed. Risoprint, Cluj-Napoca, 2007:449-455.

3. Gârd C, Dinu M, Boscencu R, Pavel M. Studiu farmacognostic comparativ asupra produsului Basilici herba şi a condimentului Bazil. Farmacia. 2003;51(4):40-48.

4. Purushothaman $B$, Prasanna Srinivasan $R$, Suganthi $P$, Ranganathan B, Gimbun J, Shanmugam K. A Comprehensive Review on Ocimum basilicum. Journal of Natural Remedies. 2018;18(3):71-85.

5. Benedec D, Oniga I, Oprean R, Tamas M, Chemical composition of the essential oils of Ocimum basilicum L. cultivated in Romania. Farmacia. 2009;57(5):625-629.

6. Benedec D, Oniga I, Toiu A, Tiperciuc B, Tămaş M, Vârban ID, Crişan G, GC-MS analysis of the essential oil obtained from Ocimum basilicum L. "Holland" cultivar. Farmacia. 2013;61(3):448-453.
7. Verma RS, Padalia RC, Chauhan A. Variation in the volatile terpenoids of two industrially important basil (Ocimum basilicum L.) cultivars during plant ontogeny in two different cropping seasons from India. J Sci Food Agric. 2011.

8. Avetisyan A, Markosian A, Petrosyan M, Sahakyan N, Babayan A, Aloyan S, Trchounian A. Chemical composition and some biological activities of the essential oils from basil Ocimum different cultivars. BMC Complement Altern Med. 2017;17:60.

9. Oniga I, Benedec D, Hanganu D, Toiu A. Analiza produselor naturale medicinale. Ed. a III-a. Editura Medicală Universitară "Iuliu Hațieganu", Cluj-Napoca, 2014.

10. Benedec D, Vlase L, Oniga I, Mot AC, Silaghi-Dumitrescu R, Hanganu D, Tiperciuc B, Crisan G. LC-MS analysis and antioxidant activity of phenolic compounds from two indigenous species of Mentha. Note I. Farmacia. 2013;61(2):262-267.

11. Benedec D, Danganu D, Filip L, Oniga I, Tiperciuc B, Olah NK, Gheldiu AM, Raita O, Vlase L. Chemical, antioxidant and antibacterial studies of Romanian Heracleum sphondylium. Farmacia. 2017;65:253-256.

12. x x x - Farmacopeea Română, Ed. a X-a, 1993. 